\title{
How Risky are Elective Endoscopic Procedures during the COVID-19 Normalization Process?
}

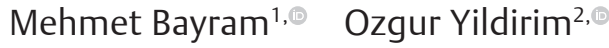

Address for correspondence Mehmet Bayram, MD, Department of Gastroenterology, Basaksehir Cam and Sakura City Hospital, Basaksehir Olimpiyat Bulvarı Way, 34480 Basaksehir/Istanbul, Turkey (e-mail: drmhbayram@gmail.com).

J Digest Endosc:2020;11:275-278

\begin{abstract}
Keywords

- elective endoscopy

- COVID-19

- risk

Objective In this study, we aimed to investigate the incidence of COVID-19 after endoscopic procedures were performed with elective indications during the normalization process of the COVID-19 pandemic. We also aimed to investigate safety of these procedures.

Materials and Methods The study included 351 patients who underwent an endoscopic procedure for elective indications in the endoscopy unit of the gastroenterology department of the İstanbul Kanuni Sultan Süleyman Training and Research Hospital and whose risk assessment for COVID-19 was low before the procedure. All patients were followed-up within 14 days after the procedure in terms of getting a COVID-19 PCR test and its results and also assessing development of any symptoms such as fever, cough, and shortness of breath associated with COVID-19.

Results A total of 351 patients were included in the study. A total of 445 procedures were performed: upper gastrointestinal (Gl) system endoscopy in 180 patients, colonoscopy in 74 patients, double procedure (upper $\mathrm{Gl}$ endoscopy + colonoscopy) in 94 patients, and percutaneous endoscopic gastrostomy (PEG) in three patients. It was found that at least one of the symptoms including cough, shortness of breath, and fever developed in 33 (9.4\%) of these 351 patients within 14 days. It was observed that 20 (5.6\%) of these 33 patients were tested for COVID-19 and the test results were reported as positive in two $(5.6 \%)$ patients.

Conclusion In the normalization process of COVID-19, elective endoscopic procedures can be performed in patients, who are shown to be low risk, by paying attention to the consummate use of the personal protective equipment (PPE).
\end{abstract}

\section{Introduction}

Coronaviruses are enveloped positive-strand RNA viruses. They include six species that cause diseases in humans. ${ }^{1}$ Among these, severe acute respiratory syndrome coronavirus 2 (SARS-CoV-2) was detected for the first time in December 2019 in China and subsequently caused an epidemic by spreading to more than 40 million people in more than 200 countries. WHO declared a global health emergency in January 2020 and also declared the novel Coronavirus outbreak a pandemic on March 2020; further, the disease name was determined as COVID-19. COVID-19 is a disease that can progress in a broad spectrum from
DOI https://doi.org/ 10.1055/s-0040-1722379 ISSN 0976-5042.

\footnotetext{
(c) 2020. Society of Gastrointestinal Endoscopy of India.

This is an open access article published by Thieme under the terms of the Creative Commons Attribution-NonDerivative-NonCommercial-License, permitting copying and reproduction so long as the original work is given appropriate credit. Contents may not be used for commercial purposes, or adapted, remixed, transformed or built upon. (https://creativecommons.org/licenses/by-nc-nd/4.0/).

Thieme Medical and Scientific Publishers Pvt. Ltd. A-12, 2nd Floor, Sector 2, Noida-201301 UP, India
} 
asymptomatic or mild disease to severe respiratory disease., ${ }^{2,3}$ The most common symptoms of disease are fever, cough, and shortness of breath. ${ }^{2}$ Patients may also experience nausea, vomiting, abdominal pain, and diarrhea as gastrointestinal (GI) system symptoms. ${ }^{4}$ The incubation period of the disease is 2 to 14 (median 5 ) days. ${ }^{5}$ The virus was detected in the stools of infected patients at a rate of up to $51 \%$ in 1 to 7 days. ${ }^{6}$ Transmission occurs by contact with droplets and aerosols containing viruses of infected person. ${ }^{7}$ It has also been found that the disease is transmitted through the fecal-oral route. ${ }^{8}$ Patients and health care workers may be exposed to potentially infectious biological material during endoscopic procedures. ${ }^{9}$ Therefore, endoscopy units are at increased risk of health care workers in terms of airway droplet infection, conjunctival contact, and potential fecal-oral transmission. ${ }^{3,8}$ Since the COVID-19 outbreak, all endoscopic procedures except emergency cases have been cancelled or postponed in our center, as in many other centers. We evaluated the frequency of COVID-19 that may occur in the postprocedure period in patients who underwent an elective (in all nonemergency indications) endoscopic procedure during the normalization process that started with leaving the peak period of the disease behind.

\section{Materials and Methods}

The study included 351 patients who underwent an endoscopic procedure for all indications except emergency cases between June 1 and August 21, 2020, at the endoscopy unit of the gastroenterology department of the Istanbul Kanuni Sultan Suleyman Training and Research Hospital. Procedures performed due to emergency indications (GI bleeding and foreign body removal) were excluded from the study. All patients were evaluated for risk stratification for COVID-19 before the procedure. ${ }^{10}$ All patients' temperature were checked before the procedure. Patients with normal fever were questioned in terms of shortness of breath, cough, and history of contact with COVID-19 patient or suspect. Patients with negative answers to all questions were considered to be at low risk and were included in the study. Patients who responded positively to one of these questions or had fever were included in the high-risk group and excluded from the study. All patients were sedated with 1 to $5 \mathrm{mg}$ of midazolam. In addition, topical pharyngeal anesthesia with xylocaine was applied to patients who underwent upper GI endoscopy. All endoscopic procedure times were recorded. All patients were questioned by inviting them to the outpatient clinic or calling by phone in terms of development of any symptoms such as fever, cough, and shortness of breath which is associated with COVID-19 or having a COVID-19 PCR test within 14 days after the procedure. All patients included in the study were followed in terms of COVID-19 testing status and results from the National Health Database. Personal protective equipment (PPE) of the entire health care staff were provided consummately (N95 respirator mask, disposable hairnet, booties/shoe covers, two pairs of gloves, waterproof disposable gowns, goggles and disposable face shield) during the endoscopic procedures. The "2-meter distance" rule was applied in patient waiting and recovery rooms. Permission was obtained from the Ministry of Health Scientific Research Platform and the local ethics committee for the study (No: 2020-07-08T12_58_15).

\section{Statistical Analysis}

All analyses were performed using SPSS version 20.0 for Windows (IBM Inc., Chicago, Illinois, USA). Chi-square test was used for comparisons of categorical variables. A value of $p<0.05$ (2-sided) was considered statistically significant.

\section{Results}

A total of 351 patients were included in the study. A total of 445 procedures were performed: upper GI system endoscopy in 180 patients, colonoscopy in 74 patients, double procedure (upper GI endoscopy + colonoscopy) in 94 patients, and percutaneous endoscopic gastrostomy (PEG) in 3 patients. A total of 181 male and 170 female patients were included in the study. The mean age of patients was 49.7. Upper GI endoscopy procedures were performed in the range of 4 to 15 (median: 6) minutes. Colonoscopy procedures were performed in the range of 9 to 43 (median: 15) minutes. At least one of the complaints such as cough, shortness of breath, and fever developed in 33 (9.4\%) patients during the inquiry and evaluation made by phone call or during the outpatient clinic control 14 days after the procedure. It was observed that 20 (5.6\%) of these 33 patients were tested for COVID-19 and the test results were reported as positive in two (5.6\%) patients. There was no statistically significant difference between the 2.9\% COVID-19 PCR test positivity found in community screening studies and the PCR positivity rate in our study $(p=0,328)$. Thirteen patients did not have the test, although they had suspicious symptoms and were advised to be tested. In the endoscopy unit, one doctor, two nurses and two assistant health workers did not develop any symptoms that could be due to COVID-19 during the study time. After it was detected that the patient was underwent procedure with COVID-19 PCR positivity (two times), all health care workers were tested for COVID-19 PCR, and all tests resulted negative. Demographic data, frequency of symptoms, and COVID-19 test results about the patients are presented in - Table 1.

\section{Discussion}

By the normalization process, elective endoscopic procedures began to be performed again, although they were less in number compared with the prepandemic period. In this study, 445 procedures were performed on 351 patients in our center, while in the same time period as this study in 2019, 811 endoscopic procedures were performed on 618 patients. Our study is the first study in the literature evaluating the risk of endoscopic procedures during the normalization period of the COVID-19 pandemic. In a study which is similar to our study and was conducted in Italy during the onset of the outbreak (January 27 to March 13, 2020), 8 of 802 patients 
Table 1 Demographic data, frequency of symptoms and COVID-19 test results about the patients

\begin{tabular}{|l|l|l|l|l|l|}
\hline & Total & $\begin{array}{l}\text { Upper GI } \\
\text { Endoscopy }\end{array}$ & Colonoscopy & $\begin{array}{l}\text { Endoscopy + } \\
\text { Colonoscopy }\end{array}$ & PEG \\
\hline Number of patients & 351 & 180 & 74 & 94 & 3 \\
\hline Number of procedures & 445 & 180 & 74 & 188 & 3 \\
\hline Age (mean) & 49.8 & 46.5 & 50.05 & 52.4 & 77.3 \\
\hline $\begin{array}{l}\text { Gender } \\
\text { M/F }\end{array}$ & $181 / 170$ & $91 / 89$ & $43 / 31$ & $46 / 48$ & $1 / 2$ \\
\hline $\begin{array}{l}\text { Presence of symptoms } \\
(n \%)\end{array}$ & $33(9.4 \%)$ & $16(9.4 \%)$ & $3(4 \%)$ & $7(11.7 \%)$ & $0(0 \%)$ \\
\hline $\begin{array}{l}\text { Patients tested for } \\
\text { COVID-19 (n\%) }\end{array}$ & $20(5.6 \%)$ & $9(5 \%)$ & $0(0 \%)$ & $2(2.1 \%)$ & $1(33.3 \%)$ \\
\hline $\begin{array}{l}\text { COVID-19 test } \\
\text { positivity (n\%) }\end{array}$ & $2(5.6 \%)$ & $0(0 \%)$ & $0(0 \%)$ & \\
\hline
\end{tabular}

Abbreviations: Gl, gastrointestinal; PEG, percutaneous endoscopic gastrostomy.

who underwent endoscopy had suspicious symptoms, and one patient who was tested was positive. Additionally, in the other part of that study, in the same period, the health care workers working in 968 endoscopy units were tested and $4.3 \%$ of them were positive for COVID-19. In that study, the relatively high positivity in health care workers was attributed to the insufficiency of PPE supply to health care workers and the lack of attention to the use of PPE in the early period of the epidemic. Also, endoscopic procedures were considered as low-risk interventions for the patient and health care workers when attention was paid to appropriate use of PPE. ${ }^{11}$ In another study, no transmission was detected among health care workers in a procedure of a patient with severe respiratory symptoms with the use of a surgical mask at a distance of less than $2 \mathrm{~m}$ and performed in less than 10 minutes. ${ }^{12}$ In our study, no transmission was detected in the endoscopy unit workers. In our study, the rate of developing suspicious symptoms in patients who underwent the procedure, the rate of testing, and the frequency of COVID-19 positivity were found to be higher than the other study. This can be explained by the fact that the other study was conducted very early in the pandemic. In a screening study which was conducted throughout our country, the rate of COVID-19 positivity in the asymptomatic population was detected to be $2.5 \%$. In Istanbul, the city where our study was conducted, this rate was found to be $2.9 \% .^{13}$ Therefore, the rate of COVID-19 occurrence (5.6\%) in patients who underwent endoscopy in our study is an expected result. Although our results are data from a single center, they may be useful in other centers when evaluated by considering community screening studies. In a study conducted in China, it was recommended that all patients before the endoscopic procedure should be screened for symptoms; also, thorax CT imaging and then COVID-19 test should be performed if there is any doubt. ${ }^{14}$ In another study, preprocedure testing is conditionally recommended with very low level of evidence in areas where asymptomatic SARS-CoV-2 infection rate is $<0.5 \% .{ }^{15}$ In other different guidelines, screening test is recommended for all patients, if it is in accordance with the country's resources and health policy. ${ }^{16}$ Considering all the departments where endoscopic procedures are performed and testing capacity of countries, pre-procedure testing for all patients can be difficult and expensive. Considering the conditions of our country, we carried out the procedure among patients who were found to be at low risk by only examining symptoms, contact and fever, without testing, and included these patients into the study. Since the start of pandemic, a postponement was recommended for elective endoscopic procedures in the guidelines. ${ }^{10,17}$ Although this postponement varies according to the indication for the procedure, guidelines recommend re-evaluation of patients after 8 weeks to 12 weeks for elective procedures. ${ }^{10,17}$ When the guidelines are evaluated in terms of the priority of the indication, the endoscopic procedure is considered as high priority in some guidelines, ${ }^{10}$ and low priority in others, ${ }^{17}$ and in patients with FOBT positive, which constitutes a significant amount of the patients. Therefore, it is controversial which process has higher priority and how long it can be postponed. Considering the uncertainty of the pandemic duration, we think that the procedures can be continued without any delay in low-risk patients as in our study. Limitations of our study are that it was conducted in a single center, and all patients who underwent endoscopic procedures were not tested regardless of the symptoms.

\section{Conclusion}

In the normalization process of COVID-19, elective endoscopic procedures can be performed by examining the presence of symptoms, contact and fever, and paying attention to the consummate use of PPE in patients who are found to be at low risk. Further studies on this subject, which are conducted in different countries and cities, are needed.

\section{Conflicts of Interest}

None declared.

\section{References}

1 Weiss SR, Leibowitz JL. Coronavirus pathogenesis. Adv Virus Res 2011;81:85-164 
2 Guan WJ, Ni ZY, Hu Y, et al; China Medical Treatment Expert Group for Covid-19. Clinical characteristics of Coronavirus disease 2019 in China. N Engl J Med 2020;382(18):1708-1720

3 Huang C, Wang Y, Li X, et al. Clinical features of patients infected with 2019 novel coronavirus in Wuhan, China. Lancet 2020;395(10223) :497-506

4 Tian Y, Rong L, Nian W, He Y. Review article: gastrointestinal features in COVID-19 and the possibility of faecal transmission. Aliment Pharmacol Ther 2020;51(9):843-851

5 Li Q Guan X, Wu P, et al. Early transmission dynamics in Wuhan, China, of novel Coronavirus-infected pneumonia. N Engl J Med 2020;382(13):1199-1207

6 Tang A, Tong ZD, Wang HL, et al. Detection of novel Coronavirus by RT-PCR in stool specimen from asymptomatic child, China. Emerg Infect Dis 2020;26(6):1337-1339

7 Wang C, Horby PW, Hayden FG, Gao GF. A novel coronavirus outbreak of global health concern. Lancet 2020;395(10223) : 470-473

$8 \mathrm{Gu}$ J, Han B, Wang J. COVID-19: Gastrointestinal manifestations and potential fecal-oral transmission. Gastroenterology 2020; 158(6):1518-1519

9 Johnston ER, Habib-Bein N, Dueker JM, et al. Risk of bacterial exposure to the endoscopist's face during endoscopy. Gastrointest Endosc 2019;89(4):818-824

10 Gralnek IM, Hassan C, Beilenhoff U, et al. ESGE and ESGENA Position Statement on gastrointestinal endoscopy and the COVID-19 pandemic. Endoscopy 2020;52(6):483-490
11 RepiciA,AragonaG,CengiaG,etal;ITALIANGI-COVID19Working Group. Low risk of COVID-19 transmission in GI endoscopy. Gut 2020;69(11):1925-1927

$12 \mathrm{Ng} \mathrm{K}$, Poon BH, Kiat Puar TH, et al. COVID-19 and the risk to health care workers: a case report. Ann Intern Med 2020; 172(11):766-767

13 Health Minister Koca: 2.5 out of every 1000 randomly tested test results were positive. Available at: https://www.aa.com.tr/ tr/koronavirus/saglik-bakani-koca-rastgele-test-edilen-her1000-kisiden-2.5 inde-test-sonucu-pozitif-cikti/1920770\#. Accessed November 5, 2020

14 Zhang S, Wu X, Pan H, et al. Gastrointestinal endoscopy infection control strategy during COVID-19 pandemic: Experience from a tertiary medical center in China. Dig Endosc 2020;(e-pub ahead of print doi: 10.1111/den.13783

15 SultanS, SiddiqueSM, AltayarO, etal.AGAInstitute Rapid Review and Recommendations on the Role of Pre-Procedure SARSCoV2 Testing and Endoscopy. Gastroenterology 2020;28:16

16 Perisetti A, Gajendran M, Boregowda U, Bansal P, Goyal H. COVID-19 and gastrointestinal endoscopies: current insights and emergent strategies. Dig Endosc 2020;32(5):715-722

17 Sultan S, Lim JK, Altayar O, et al . AGA Institute Rapid Recommendations for Gastrointestinal Procedures During the COVID-19 Pandemic. Gastroenterology 2020;32:739-758 